\title{
CIRCULAÇÃO E RECEPÇÃO LITERÁRIA COMO FORMA DE PROCEDIMENTO ARTÍSTICO NO CASO DE FERNANDO PESSOA
}

\author{
LITERARY PLACEMENT AND RECEPTION \\ AS ARTISTIC PROCEDURE IN \\ FERNANDO PESSOA'S CASE
}

Gabriel Ortiz Voser ${ }^{1}$

\begin{abstract}
RESUMO
Baseado em uma específica perspectiva de análise, o presente trabalho visa demonstrar que a realização "performativa" da dramaturgia heteronímica de Fernando Pessoa como a compreendemos somente foi possível devido ao suporte em que se veicularam os textos: sua publicação dispersa em diversas revistas/jornais de literatura em diferentes localidades e por um período prolongado.
\end{abstract}

PALAVRAS-CHAVE: veiculação literária; refuncionalização; arte em campo expandido

\section{ABSTRACT}

Based on a specific perspective of analysis, this paper aims to demonstrate that the "performative" realization of Fernando Pessoa's heteronomic dramaturgy as we understand was only possible due to the support in which the texts were conveyed: their publication dispersed in several literature journals in different localities and for an extended period.

KEYWORDS: literary placement; refunctionalization; art in expanded field 


\section{PRINCÍPIOS}

Declarou o escritor português Fernando Pessoa, em carta a um amigo no ano de 1931, que tinha em conta a si mesmo como um autor de teatro mais do que tudo:

(...) O ponto central da minha personalidade como artista é que sou um poeta dramático; tenho continuamente, em tudo quanto escrevo, a exaltação íntima do poeta e a despersonalização do dramaturgo. Vôo outro - eis tudo. Do ponto de vista humano - em que ao crítico não compete tocar, pois de nada lhe serve que toque - sou um hístero-neurastênico com a predominância do elemento histérico na emoção e do elemento neurastênico na inteligência e na vontade (minuciosidade de uma, tibieza de outra). Desde que o crítico fixe, porém, que sou essencialmente poeta dramático, tem a chave da minha personalidade, no que pode interessá-lo a ele, ou a qualquer pessoa que não seja um psiquiatra, que por hipótese, o crítico não tem que ser. Munido desta chave, ele pode abrir lentamente todas as fechaduras da minha expressão. Sabe que, como poeta, sinto; que, como poeta dramático, sinto despegando-me de mim; que, como dramático (sem poeta), transmudo automaticamente o que sinto para uma expressão alheia ao que senti, construindo na emoção uma pessoa inexistente que a sentisse verdadeiramente, e por isso sentisse, em derivação, outras emoções que eu, puramente eu, me esqueci de sentir. (PESSOA, 1974, p. 66)

"Munido desta chave" - associada a outras duas referências teóricas - é que se apresenta, neste trabalho, uma compreensão específica acerca do que se define como a "encenação performativa" da dramaturgia heteronímica de Fernando Pessoa e, especialmente, de como a sua realização foi somente possível em função do suporte utilizado no processo: a publicação dispersa em diversas revistas e jornais de literatura em três cidades distintas e pelo período prolongado de vinte e três anos.

Nosso argumento será apresentado em diferentes momentos: 1) no qual se assinala em nosso horizonte teórico a presença da noção de "refuncionalização" de aparelhos intelectuais/artísticos de produção (BENJAMIM, 1996, p. 33-44) como referência conceitual; 2) em que apresentamos as noções de "campo expandido" (QUILICI, 2014, p. 12-21) e "arte-arte/arte-vida" (KAPROW, 1993, p. 211-243) como chave interpretativa no processo de identificação da "encenação performativa" da dramaturgia em "campo expandido" dos heterônimos do poeta; 3) em que discutiremos a concepção do próprio poeta (PESSOA, 1974, p. 66-92) relativa ao processo produtivo de sua escrita dramática (no caso específico da dramaturgia heteronímica); e, 4) em que observaremos, finalmente, como o processo de veiculação (circulação e recepção) dispersa e esparsa dos textos heteronímicos se situa, em consonância com a concepção geral do "projeto" do escritor português, como elemento fundamental para a sua produção e efetiva realização. 


\section{REFUNCIONALIZAÇÃO DE APARELHOS DE PRODUÇÃO}

Um aparelho de produção intelectual e/ou artístico (a literatura ou o teatro, por exemplo) raramente é criação de um determinado artista; ao contrário, costuma fazer-se presente como um meio de produção que, social, histórica e culturalmente instituído, antecede tanto a prática quanto o pensamento de quem, por meio dele, produz. Ao sustentar tal argumento, Walter Benjamin (1985, p. 120-136) afirma que os meios convencionais de produção podem sofrer alterações estruturais em virtude de determinados processos de "refuncionalização" de seus respectivos aparelhos produtivos, como no caso - indica o filósofo - do teatro épico de Bertolt Brecht, em que uma ênfase atribuída ao elemento narrativo na obra dramatúrgica reconfigura a poética dramática tanto em termos literários quanto no que diz respeito a processos de encenação, na medida em que, como decorrência dessa refuncionalização, o papel social do ator se desloca da posição de intérprete de personagens dramáticos - assim ultrapassando a função de instrumento de representação - e assume um lugar de interlocução com o público, ocupando nova e ambígua posição na qual se situa entre as dimensões da ficção - no caso, do drama, da encenação - e a da realidade social em que o próprio evento teatral tem lugar. Esse fenômeno de apropriação e reconfiguração do aparelho de produção como ocasionado por meio da prática brechtiana é o que, por sua autenticidade, determina, conforme Benjamin, a disposição artística característica do trabalho de um "autor-produtor".

A melhor tendência é falsa quando não prescreve a atitude que o escritor deve adotar para concretizar essa tendência. E o escritor só pode prescrever essa atitude em seu próprio trabalho: escrevendo. A tendência é uma condição necessária, mas não suficiente, para o desempenho da função organizatória da obra. Esta exige, além disso, um comportamento prescritivo, pedagógico, por parte do escritor. Essa exigência é hoje mais imperiosa que nunca. Um escritor que não ensina outros escritores não ensina ninguém. O caráter modelar da produção é, portanto, decisivo: em primeiro lugar, ela deve orientar outros produtores em sua produção e, em segundo lugar, precisa colocar a disposição deles um aparelho mais perfeito. Esse aparelho é tanto melhor quanto mais conduz consumidores à esfera da produção, ou seja, quanto maior for sua capacidade de transformar em colaboradores os leitores ou espectadores. Já possuímos um modelo desse gênero, do qual só posso falar aqui rapidamente. É o teatro épico de Brecht. (BENJAMIN, 1985, p. 131-132)

Assim, para Benjamin, quanto mais o uso criativo de um modelo operativo puder promover uma crise de sentidos e significados dentro do próprio regime discursivo em que se articula, mais "perfeito" ele será, na medida em que revele novas possibilidades criativas, como a possibilidade de incluir como criadores-parceiros - como fez Brecht - os fruidores de uma obra, os quais Benjamin inicialmente define como "consumidores". 
Walter Benjamin defende ainda que a regular utilização de aparelhos de produção previamente instituídos pode muitas vezes estar a serviço de uma tendência política meramente conservadora - ou "reacionária", como definiu - em que o artista apenas atua como um usuário de modelos discursivos, de maneira "informativa". Para o pensador, o artista somente assume uma função operativa criadora - "revolucionária”, na sua terminologia - na medida em que atue por intermédio de procedimentos de criação de modelos de produção ou de refuncionalização dos aparelhos de produção disponíveis, pois, ao contrário de "abastecer um aparelho produtivo", cria um que lhe seja próprio ou modifica e transforma algum já existente, convertendo-o, desse modo, em outro, recriado por usos que redimensionem sua potência, não em consequência de uma ou de outra "tendência", mas do próprio impulso criador e de necessidades artísticas próprias ao projeto em curso - como Benjamin pôde observar na obra de Brecht.

\section{CAMPO EXPANDIDO EM ARTE-ARTE E EM ARTE-VIDA}

O que marca as vanguardas artísticas do século XX (como o futurismo, o dadaísmo e o surrealismo) em termos de uso dos aparelhos produtivos à disposição dos artistas é um estado de abertura, de indeterminação, diante das possibilidades de uso dos meios de produção desenvolvidos em diferentes épocas até o seu presente. A partir de então, tal abertura para o indeterminado da criação conduziu à indefinição de estilos: não há um "estilo" futurista, surrealista, dadaísta, etc.; o que passa a orientar o trabalho dos artistas das diversas tendências, antes de normas prescritivas de produção, são noções relativas à posição que cada artista e/ou grupo assume no contexto da vida política.

No decorrer do século XX, em categorias das artes visuais como a pintura e a escultura, artistas passaram a trabalhar muito mais orientados pelas possibilidades de uso instrumental de seus aparelhos produtivos do que pela busca de resultados, muito mais interessados na operação dos meios do que realização de fins determinados - inclusive porque o uso aberto e indeterminado dos meios expandia os possíveis da arte na direção de fins inéditos os quais chegavam a vencer as fronteiras entre as modalidades artísticas como estabelecidas na tradição canônica, expandindo, assim, as possibilidades de cada campo.

De acordo Cassiano Quilici, os processos de criação e produção de arte em campo expandido dizem respeito a “(...) fazer transbordar práticas artísticas para fora dos circuitos e dos sentidos que lhe são habitualmente atribuídos, inserindo-as em lugares insuspeitos, articulando-as com outras formas de saber e fazer (...)” (QUILICI, 2014, p. 12).

Os questionamentos sucessivos de estéticas normativas, convenções cristalizadas, instituições, territórios, ajudam a alimentar a constante perplexidade diante da "coisa" que chamamos arte. Abre-se espaço para reinvenções de seu conceito, articulando-o com dimensões mais amplas da cultura e da vida. (QUILICI, 2014, p. 16) 
Uma discussão acerca das reinvenções do conceito de arte e sua articulação com as "dimensões mais amplas da cultura e da vida", como descreve Quilici, foi desenvolvida por Allan Kaprow (1993, p. 201-218) em $O$ experimento do real ${ }^{2}$, onde o artista estabelece uma distinção radical entre dois processos distintos - e ideais - de se produzir arte: "artlike art" e "lifelike art", definidos como tendências que se mantêm por "filosofias de realidade"4 (KAPROW, 1993, p. 201) fundamentalmente contrastantes:

Dito de forma simplista, a arte-arte ${ }^{5}$ sustenta que a arte está separada da vida e de tudo o mais, enquanto a arte-vida sustenta que a arte está conectada à vida e a tudo o mais. Em outras palavras, existe arte a serviço da arte e arte a serviço da vida. Quem faz arte-arte tende a ser especialista, quem faz arte-vida, generalista. (KAPROW, 1993, p. 201)

Em Kaprow - num resumo extremo -, a arte-arte opera [idealmente] de acordo com as normas canônicas e sob os seus ditames regulamentais: é produzida com os suportes e instrumentos tidos como os mais adequados e pode ser vista em locais próprios para isso durante os períodos devidos (museus, galerias, salas de concerto, teatros e assim por diante); ao passo que a arte-vida opera fora dos padrões tradicionais e além dos limites convencionais. De acordo com Kaprow, "a raiz da comunicação de todo trabalho arte-arte é a separação e o especialismo (...); e o correspondente de toda a arte-vida é conectividade e sensibilização de grande angular". Arte-arte define-se sempre por obra, enquanto arte-vida diz respeito a "acontecimentos" e "processos" (KAPROW, 1993, p. 204).

\section{PONTE (UM COMENTÁRIO DE TRANSIÇÃO)}

Dinâmicas de refuncionalização de aparelhos produtivos como as percebidas por Walter Benjamin no teatro (literatura dramática e encenação) de Bertolt Brecht evidenciam que, por meio de procedimentos artísticos específicos, é um tipo de uso desobediente a normas e conceitos canônicos - um tipo de uso "anárquico" - dos recursos disponíveis no âmbito de uma disciplina artística o que revela, em uma obra, sua tendência criativa, renovadora, transformadora, vivificadora, ou meramente conservadora. Assim como Benjamin identificou na obra de Brecht novos possíveis no âmbito da linguagem teatral (texto e cena), pudemos perceber ${ }^{6}$ processos análogos de refuncionalização ocorridos na obra de Fernando Pessoa, especificamente no que diz respeito à dramaturgia heteronímica e ao processo que designamos como a "encenação performativa" dessa dramaturgia de "campo expandido". Essa observação foi somente possível em razão da atualidade da pesquisa, pois dependeu necessariamente do vínculo entre a nossa mirada e referências associadas à teoria da performance art na contemporaneidade, como também - além das que acabamos de ver - o conceito de programa performativo: o programa performativo é descrito por Eleonora Fabião 
(2013, p. 1-11) como um procedimento em que é a interatividade - ou, pelo menos, a interligação - entre os elementos presentes a uma performance o fator que determina a sua existência como acontecimento - e, nesse caso, o acontecimento em torno de - ou integrado a - uma peça artística (seja qual for o seu gênero) é o que define a obra, e não a peça em si.

Muito objetivamente, o programa é o enunciado da performance: um conjunto de ações previamente estipuladas, claramente articuladas e conceitualmente polidas a ser realizado pelo artista, pelo público ou por ambos sem ensaio prévio. $\mathrm{Ou}$ seja, a temporalidade do programa é muito diferente daquela do espetáculo, do ensaio, da improvisação, da coreografia. "Vou sentar numa poltrona por 3 dias e tentar fazer levitar um frasco de leite de magnésia. No sábado às 17:30 me levantarei". É este programa/enunciado que possibilita, norteia e move a experimentação. Proponho que quanto mais claro e conciso for o enunciado - sem adjetivos e com verbos no infinitivo - mais fluida será a experimentação. Enunciados rocambolescos turvam e restringem, enquanto enunciados claros e sucintos garantem precisão e flexibilidade. (FABIÃO, 2013, p. 4 - grifos da autora)

Tendo em vista, portanto, o nosso horizonte teórico - a ideia de "refuncionalização" em Walter Benjamin, o conceito de "campo expandido" de Rosalind Krauss como abordado por Cassiano Quilici, as formulações de Alan Kaprow em torno o modelo compreensivo "arte-arte/arte-vida" e o conceito de programa performativo elaborado por Eleonora Fabião -, voltamos ao desenvolvimento de nossa análise acerca do modelo operativo de produção de Fernando Pessoa quanto à dramaturgia heteronímica.

\section{A HETERONÍMIA DE FERNANDO PESSOA: DRAMATURGIA EM CAMPO EXPANDIDO}

Nesta seção, enquanto houver palavras do autor para descrever seus próprios procedimentos de produção relativos à concepção da dramaturgia dos heterônimos, a elas daremos prioridade e delas faremos uso em detrimento das nossas, que terão lugar - as nossas - somente para relacionar os argumentos do próprio autor, pois que ninguém melhor que ele mesmo a expor o próprio ponto de vista.

Do volume Obras em prosa (PESSOA, 1974), consta no capítulo Gênese e justificação da heteronímia, na seção intitulada Apresentação dos heterônimos, um texto - Aspectos - o qual consiste, conforme indicação do editor, num prefácio do autor para uma (então futura) - projetada por Pessoa - edição das suas obras (sendo este prefácio possivelmente datado de 1931), em que se observa essa relação de descontinuidade entre conteúdos e gêneros (entre matéria e forma): o caráter dramático da heteronímia, que corresponde à relação dialógica entre os personagens de um drama conven- 
cional, não é demonstrado - como é comum no gênero dramático - por meio de uma escrita que apresente ao público, no contexto de um drama teatralmente encenado, o "presente" das relações intersubjetivas entre os personagens (no caso, heteronímicos).

A obra complexa, cujo primeiro volume é este, é de substância dramática, embora de forma vária - aqui de trechos em prosa, em outros livros de poemas ou de filosofias. É, não sei se um privilégio se uma doença, a constituição mental que a produz. O certo, porém, é que o autor destas linhas - não sei bem se o autor destes livros - nunca teve uma só personalidade, nem pensou nunca, nem sentiu, senão dramaticamente, isto é, numa pessoa, ou personalidade, suposta, que mais propriamente do que ele próprio pudesse ter esses sentimentos. Há autores que escrevem dramas e novelas; e nesses dramas e nessas novelas atribuem sentimentos e ideias às figuras, que as povoam, que muitas vezes se indignam que sejam tomados por sentimentos seus, ou ideias suas. Aqui a substância é a mesma, embora a forma seja diversa. A cada personalidade mais demorada, que o autor destes livros conseguiu viver dentro de si, ele deu uma índole expressiva, e fez dessa personalidade um autor, com um livro, ou livros, com as ideias, as emoções, e a arte dos quais, ele, o autor real (ou porventura aparente, porque não sabemos o que seja a realidade), nada tem (...). (PESSOA, 1974, p. 81-82)

A edição das obras completas, a que estaria destinado o texto desse prefácio, jamais se realizou sob a supervisão do autor, que veio a falecer antes de que fosse tal empresa levada a termo. No entanto, o texto permite perceber, por meio da declarada concepção do autor, alguns procedimentos de refuncionalização, se temos como referência o conceito benjaminiano.

Notamos que os personagens de Pessoa não estão circunscritos aos limites de um drama como se estabelece na tradição da literatura dramática, pois, para o autor, os heterônimos são como pessoas vivas, que vivem a mesma vida dos cidadãos portugueses seus contemporâneos, têm biografias próprias e suas histórias de vida são interligadas.

Tenho, na minha visão a que chamo interior apenas porque chamo exterior a determinado "mundo", plenamente fixas, os traços de caráter, a vida, a ascendência, nalguns casos a morte, destas personagens. Alguns conheceram-se uns aos outros; outros não. A mim, pessoalmente, nenhum me conheceu, exceto Álvaro de Campos. Mas, se amanhã eu, viajando na América, encontrasse subitamente a pessoa física de Ricardo Reis, que, a meu ver, lá vive, nenhum gesto de pasmo me sairia da alma para o corpo; estava certo tudo, mas, antes disso, já estava certo. O que é a vida? (PESSOA, 1974, p. 83-84)

Na concepção do autor, os heterônimos estabelecem entre si relações dramáticas, e tais relações fazem-se notar por meio dos próprios textos, dos estilos e da "personalidade" de cada um deles, como fica perfeitamente claro na descrição do próprio autor: 
As obras heterónimas de Fernando Pessoa são feitas por, até agora, três nomes de gente - Alberto Caeiro, Ricardo Reis, Álvaro de Campos. Estas individualidades devem ser consideradas como distintas da do autor delas. Forma cada uma uma espécie de drama; e todas elas juntas formam outro drama. Alberto Caeiro, que se tem por nascido em 1889 e morto em 1915, escreveu poemas com uma, e determinada, orientação. Teve por discípulos - oriundos, como tais, de diversos aspectos dessa orientação - aos outros dois: Ricardo Reis, que se considera nascido em 1887, e que isolou naquela obra, estilizando, o lado intelectual e pagão; Álvaro de Campos, nascido em 1890, que nela isolou o lado por assim dizer emotivo, a que chamou "sensacionista", e que - ligando-o a influências diversas, em que predomina, ainda que abaixo da de Caeiro, a de Walt Whitman - produziu diversas complicações, em geral de índole escandalosa e irritante, sobretudo para Fernando Pessoa, que em todo o caso não tem remédio senão fazê-las e publicá-las, por mais que delas discorde. As obras destes três poetas formam, como se disse, um conjunto dramático; e está devidamente estudada a entreacção intelectual das personalidades, assim como as suas próprias relações pessoais. Tudo isto constará de biografias a fazer, acompanhadas, quando se publiquem, de horóscopos e, talvez, de fotografias. É um drama em gente, em vez de em actos. (Se estas três individualidades são mais ou menos reais que o próprio Fernando Pessoa - é problema metafísico, que este, ausente do segredo dos Deuses, e ignorando portanto o que seja realidade, nunca poderá resolver). (PESSOA, 1993, p. 250)

O autor tem clara, para si, a relação dramática entre seus personagens, mas como, no contexto do drama que lhes é próprio, eles estão "vivos", e por isso mesmo em constante devir - tanto eles mesmos como suas obras, sendo continuamente escritas - não lhes é possível a existência limitada em um texto dramático convencional, pois o suporte tradicional do gênero literário a que deveriam pertencer, não pode compreender personagens "vivos", cuja vida permanece ainda inacabada. Assim, Pessoa precisa superar essa limitação do aparelho produtivo disponível, e é o que ele faz tomando, para prática de escrita do gênero dramático que lhe é próprio - porém incompatível com sua autêntica concepção de "drama" -, dois gêneros literários "estranhos" à noção convencional de drama: o "lírico" e "épico" (narrativo) 7.

Procedamos, então, a analisar as razões pelas quais a dramaturgia da heteronímia se realiza por meio do gênero lírico: uma vez que os personagens do drama apenas muito raramente dialogam diretamente entre si, o que eles fazem é escrever (poemas, contos, filosofias), de modo que é o gênero lírico o gênero que realiza a expressão dramática dos personagens, de modo que é por intermédio da leitura das "obras" (da lírica, portanto sendo essa lírica praticada em verso ou prosa) de cada heterônimo que se pode inferir - gradual e cada vez mais profundamente, conforme o acesso aos textos dispersos - as relações dramáticas que entre eles se estabelece. 
Assim, é possível perceber que as relações dramáticas entre os personagens heteronímicos se realizam ainda em outra dimensão - a épica (narrativa); essa dimensão épica da dramaturgia heteronímica é pelo autor projetada conscientemente ou não - ao processo de recepção da obra, pois é somente o leitor, à medida que tenha acesso às "obras" de cada heterônimo, poderá inferir e, portanto, narrar - mesmo que para si mesmo; mesmo que sem dar por isso - o drama que se estabelece na dinâmica entre-textos a qual, gradativamente é disponibilizada, como se nota, a um processo de "edição", de "montagem", onde cada leitor realiza conforme os textos heteronímicos que venha a ler e conforme a ordem em que essa recepção se dê. Em outras palavras: a dimensão em que o gênero épico (narrativo) integra a dramaturgia dos heterônimos se realiza como uma proposição performativa do autor, que disponibiliza, por intermédio da veiculação dos textos, os elementos que o leitor ordenará, dando sempre forma interior e particular (inseparável da particularidade do acesso de cada leitor) à totalidade - possivelmente sempre incompleta e inacabada - da dramaturgia heteronímica.

\section{CIRCULAÇÃO E RECEPÇÃO COMO PROCEDIMENTO ARTíSTICO}

Na concepção do autor - como vimos na seção anterior -, os heterônimos, embora fictícios, habitam um "drama" situado no interior da dimensão do real; integram, portanto, a mesma dimensão em que vivem os leitores. Por assim dizer, "vivem a mesma vida" que as pessoas de carne e osso que eventualmente leiam "seus" escritos. Assim, o contexto, o cenário do drama heteronímico é a própria vida - vários textos dos personagens heteronímicos, inclusive, tematizam eventos reais. Dessa maneira, a forma operacional em que se dá a "encenação" do drama se estabelece por intermédio tanto do processo de produção quanto do processo de recepção.

Curiosamente, em carta escrita a um amigo no ano de 1915 - em contexto diverso, evidentemente -, Pessoa expressa-se por meio de palavras que, mediante a nossa leitura posterior, permitem perceber com nitidamente os procedimentos que o artista veio a praticar durante o processo de realização de sua "obra complexa" - a saber: a encenação performativa da dramaturgia heteronímica; a carta, vista através da lente do nosso estudo, mais parece uma declaração de princípios operativos, a sua proposição artística, o seu programa performativo:

Nesta explicação aparentemente preliminar vai já exposta uma grande parte do problema. Não sei como lho hei-de expor ordenadamente; de modo perfeitamente lúcido. Mas, como isto é uma carta, eu irei expondo conforme possa; e você ordenará, em seu espírito, depois, os dispersos e alterados elementos. (PESSOA, 1974, p. 53)

Pois foi exatamente esse procedimento que Pessoa, associado a seus parceiros - os editores de cerca de trinta periódicos (entre revistas e jornais literários), adotou, publicando os textos dos personagens heteronímicos (e 
também os “seus próprios", pois o Pessoa, ele mesmo, é também um personagem heteronímico) em três das maiores cidades portuguesas (Lisboa, Porto e Coimbra) entre 1912 e 1935 (ano em que veio a falecer): o autor e seus editores gradativamente disponibilizaram ao "uso" as diferentes "cenas" da dramaturgia dos heterônimos para que cada leitor, mediante o acesso a cada texto publicado, ocasional ou sistematicamente, pudesse compor, de maneira gradativa e individual, a "sua" totalidade (particular de cada leitura) do drama heteronímico.

Recolhendo trechos da referida carta a Armando Côrtes-Rodrigues em nove de janeiro de 1915, podemos perfeitamente imaginar a composição do que teria sido o programa performativo de Fernando Pessoa, realizado por meio da veiculação de seus textos em revistas e jornais durante os vinte e três anos em que esse procedimento se manteve. Numa proposição performativa, Pessoa apresentaria sua proposta não aos "consumidores" da obra - como definiu Benjamin - mas aos (leitores? espectadores?) fruidores, criadores-parceiros, partícipes dessa grande performance (peço "licença poética” para apresentar a fictícia proposição performativa na forma de uma citação - como se fora escrita pelo poeta - em que se encontram grafadas em itálico as palavras de seu próprio punho):

Aqui, no marco inicial da realização desta obra - o drama dos meus heterônimos -, no que diz respeito à sua totalidade, caro colaborador, não sei como lho hei-de expor ordenadamente; de modo perfeitamente lúcido. No entanto, irei expondo conforme possa, publicando dispersos, de hoje até o dia da minha morte, os textos de cada "cena" na medida em que seja possível, em diversificados jornais e revistas de literatura - alguns deles publicados cá em Lisboa e outros em Porto e Coimbra -, $e$ você, conforme acesse, nesses periódicos, os escritos de cada personagem ao longo do tempo que virá, ordenará, depois, em seu espírito, os dispersos e alterados elementos.

Realizado a partir de tal proposição, o programa performativo de Pessoa se abre ao infinito, pois tantas serão as versões da "montagem", da "encenação" da dramaturgia heteronímica quantas forem suas leituras.

Antes de concluir nossa apresentação, cabe ainda lembrar que, na perspectiva dos conceitos operados pela teoria da arte contemporânea, a "peça" de Pessoa não apenas é "editada" pelos leitores na medida do acesso aos textos, mas também insere - ou, melhor, incorpora - os fruidores à sua dimensão interior, dissolvendo as fronteiras entre ficção e real.

Imagine-se, por exemplo, um momento em que, no ano de 1925, um leitor qualquer toma em mãos, ainda por exemplo, o $\mathrm{n}^{\circ} 5$ da revista Athena, $\mathrm{e}$ depara-se com alguns poemas de uma tal (heterônimo) Alberto Caeiro. Ou, antes, em 1922, um leitor toma o também no 5 mas da revista Contemporânea, em que o (heterônimo) engenheiro Álvaro de Campos tem publicada uma sua carta ao editor daquela mesma revista onde critica - o Álvaro de Campos - o comentário de Fernando Pessoa (publicado no número anterior 
da revista) ao livro do escritor Antônio Botto (esse, por sua vez, uma pessoa de carne e osso). Nesses dois momentos imaginados (mas bastante parecidos a outros certamente muitas vezes acontecidos) seria perfeitamente possível que um narrador exterior ao processo - pois que a encenação performativa da dramaturgia heteronímica dá-se, em última instância, na dimensão da narratividade do observador - observasse uma dessas cenas - essas, sim, as verdadeiras "cenas" ocasionadas pela proposição performativa identificada - e afirmasse com tranquilidade que o leitor (o cidadão real com a revista em mãos) é, pois, em virtude da sua condição mesma no interior da ação, outro personagem, interior ao drama, uma vez que ele (o leitor) é a quem se dirige diretamente - digo, em discurso direto e, nesse caso, dentro do gênero dramático - a "voz" do personagem - a qual, essa "voz", mediada pelo papel impresso da revista - ali, naquele agora imediato da leitura, com ele dialoga em cena aberta.

\section{REFERÊNCIAS BIBLIOGRÁFICAS}

BENJAMIN, Walter. "O autor como produtor" In: Magia e técnica, arte e política: ensaios sobre literatura e história da cultura. Vol.1. Trad.: Sérgio Paulo Rouanet. São Paulo: Brasiliense, 1985).

FABIÃO, Eleonora. "Programa performativo: o corpo em experiência" In: ILINXS, Revista do Lume, n.4, dez, Campinas, UNICAMP, 2013.

KAPROW, Allan. “The real experiment” In: Essays on the blurring of art and life. Los Angeles: University of California Press, 1993.

KRAUSS, Rosalind. "Sculpture in the expanded field" In: October 8, New York, (spring) 1979.

PESSOA, Fernando. Obras em prosa. Volume único. Rio de Janeiro: Companhia José Aguilar Editora, 1974.

. “Tábua bibliográfica” Presença, no 17. Coimbra: Dez. 1928 (ed. facsimil. Lisboa: Contexto, 1993).

QUILICI, Cassiano. "O campo expandido: arte como ato filosófico" In: Sala Preta, v.14, n.2. São Paulo, ECA-USP, 2014.

ROSENFELD, Anatol. O teatro épico. São Paulo: Perspectiva, 1985.

SZONDI, Peter. Teoria do drama moderno: 1880 - 1850. São Paulo: Cosac \& Naify, 2001.

Recebido para avaliação em 31/10/19 Aprovado para publicação em 14/01/20

\section{NOTAS}

${ }^{1}$ Mestre em Artes da Cena [Teoria e Crítica] pelo PPGAC-ECO-UFRJ e Doutorando em Educação [Filosofia da Educação] pelo PPGE-UFJF (bolsa UFJF). 
2 No original, The Real Experiment (tradução minha). A expressão, a meu ver, tem duplo sentido no idioma em que foi escrita, pois poderia traduzir-se também por "o verdadeiro experimento" ou "o experimento real"; aqui, porém, faço opção pelo sentido que me pareceu próximo da argumentação contida no texto.

3 No original, "Artlike Art” e Lifelike Art”.

4 No original, philosophies of reality (tradução minha).

5 Os termos Artlike Art e Lifelike Art poderiam traduzir-se como "arte tal qual a arte", por exemplo, ou então "arte similar à arte (no primeiro caso) e "arte tal qual a vida" ou "arte similar à vida" (no segundo); apesar disso, opto por traduzi-los - com a finalidade de "limpar" a leitura - por arte-arte e arte-vida.

6 Em pesquisa anterior, realizada em nível de mestrado junto ao Programa de Pós-graduação em Artes da Cena da Universidade Federal do Rio de Janeiro.

7 Nossa classificação de gênero dramático (SZONDI, 2001), refere-se à sua categorização moderna: os gêneros lírico, épico (narrativo) e dramático - os quais, ao nosso ver, resumem e atualizam as categorizações concernentes aos estudos clássicos, em que - conforme Anatol Rosenfeld (1965) - distingue-se, na poesia, a épica (que compreende, por exemplo, narrativas em verso de peripécias heróicas), a lírica (que compreende as odes: versos que exprimem as emoções e os sentimentos do próprio poeta, acompanhados de flauta ou lira) e a dramática (que compreende principalmente a tragédia e a comédia: versos que combinam a narrativa épica - manisfestada pelo Coro - e a expressão da voz lírica - manifestada por intermédio de personagens). 